\title{
Examining the Differential Longitudinal Performance of Directive versus Empowering Leadership in Teams
}

\author{
NATALIA M. LORINKOVA \\ Management \& IS Department \\ School of Business Administration \\ Wayne State University \\ Detroit, Michigan 48202 \\ e-mail: natalia.lorinkova@wayne.edu \\ MATTHEW J. PEARSALL \\ Department of Organizational Behavior \\ Kenan-Flagler Business School \\ University of North Carolina \\ Chapel Hill, NC 27599 \\ Phone: (919) 962-4312 \\ e-mail: matthew_pearsall@unc.edu \\ HENRY P. SIMS \\ Management \& Organization Department \\ Robert H. Smith School of Business \\ University of Maryland \\ College Park, MD 20742-1815 \\ e-mail: hsims@rhsmith.umd.edu
}

Author's Note: We would like to thank Ray Sparrowe and three anonymous reviewers for their insights and improvements during the review process. We are also grateful to Subra Tangirala for his feedback and comments and to John Hollenbeck, Matthias Spitzmuller, and Chris Barnes for their generous advice and support for our simulation. 


\title{
Examining the Differential Longitudinal Performance of Directive versus Empowering Leadership in Teams
}

\begin{abstract}
This study integrates theories from the leadership and team development literatures to resolve ambiguity regarding the relative benefits of empowering and directive leadership in teams by focusing on their influence on team development processes over time. Empirical results based on longitudinal performance data from 60 teams suggest that teams led by a directive leader initially outperform those led by an empowering leader. However, despite early performance losses, teams led by an empowering leader experience higher performance improvement over time due to higher levels of team learning, coordination, empowerment, and mental model development. Implications for current and future team leadership research are discussed.
\end{abstract}


In response to the increasing organizational reliance on teams to perform complex tasks, leadership research has gradually shifted its focus towards examining the important role of leaders in improving team performance and adaptation (e.g., Burke, Stagl, Klein, Goodwin, Salas, \& Halpin, 2006; Klein, Ziegert, Knight, \& Xiao, 2006). Team leadership research has concentrated on the leader behaviors that promote, develop, and maintain team performance, and two distinct approaches - empowering and directive leadership - have assumed special importance (Srivastava, Bartol, \& Locke, 2006; Yun, Faraj, \& Sims, 2005).

Empowering leadership involves sharing power with subordinates and raising their level of autonomy and responsibility, and manifests through specific behaviors such as encouraging subordinates to express opinions and ideas, promoting collaborative decision making, and supporting information sharing and teamwork (Arnold, Arad, Rhoades, \& Drasgow, 2000; Chen, Sharma, Edinger, Shapiro, \& Farh, 2011; Pearce et al., 2003; Yun et al., 2005). Empowering leadership tends to create psychological ownership in the task, heightened efficacy and commitment, and higher levels of coordination and collective information processing (e.g., Cohen, Chang, \& Ledford, 1997; Zaccaro, Rittman, \& Marks, 2001).

Directive leadership, on the other hand, is associated with the leader's positional power and is characterized by behaviors aimed at actively structuring subordinates' work through providing clear directions and expectations regarding compliance with instructions (e.g., House, 1971; Pearce et al., 2003; Somech, 2006; Yukl \& Falbe, 1991). Directive leaders help followers resolve task and role ambiguity and provide external monitoring and feedback on their performance, reducing process loss and allowing the team to execute decisions more quickly (House, 1996; Kahai, Sosik, \& Avolio, 2004; Sagie, 1997). 
Although researchers and the practitioner-oriented literature have advocated empowering over directive leadership, the empirical evidence has not fully supported this view and it is not clear that empowering leadership is actually better for enhancing team performance (e.g., Ensley, Hmieleski, \& Pearce, 2006; Kahai et al., 2004; Mathieu, Gilson, \& Rudy, 2006; Yun et al., 2005). The extant leadership research has thus far neglected two important issues which may help shed light on this question. First, the literature has generally taken a cross-sectional perspective on leader effectiveness, focusing on whether directive or empowering leaders are beneficial overall, but overlooking the question of when empowering leadership might be most or least effective. Second, although research acknowledges the importance of team member skills and attitudes in the effectiveness of various leadership approaches (e.g., Thompson \& Vecchio, 2009), it has yet to examine the direct influence leaders have on the development process of the team, and why empowering leadership may provide its promised benefits to teams over time (e.g., Klein et al., 2006; Yukl \& Lepsinger, 2004). This is especially true for newly formed teams, where time plays a critical role in understanding the interplay between team development and leadership (e.g., Kozlowski, Gully, Nason, \& Smith, 1999; Kozlowski, Gully, Salas, \& Cannon-Bowers, 1996; Yukl \& Lepsinger, 2004).

In response, we address these key conceptual and empirical problems by (a) examining the relative influence of empowering and directive leadership on the performance of teams over multiple phases of team interaction and development and (b) identifying critical behavioral, motivational, and cognitive mechanisms that explain the differences between empowering and directive leadership in teams over time. Because of the influence of leaders on internal team processes and emergent states (e.g., Mathieu, Maynard, Rapp, \& Gilson, 2008), the choice of 
leadership approach within any focal phase of team development will have implications for both current and future team interactions and performance.

Therefore, based on Kozlowski et al.'s (1999) model of team compilation and adaptation, we offer a more nuanced description of the costs and benefits of empowering leadership in teams by first arguing that the initial guidance and role definitions provided by directive leaders will help their teams to outperform empowered teams in the short term. However, due to the shared learning and decision-making climate that empowering leaders create in the initial phases of team development, and the resultant emergence of collective states and processes within the team, we argue that empowered team members will be able to attain higher levels of performance through the later phase of team development, while teams with directive leaders will be less able to improve. We then identify behavioral, motivational, and cognitive processes and states within the team that explain the improved performance of empowering versus directive leadership over time: team learning, behavioral coordination, psychological empowerment, and team mental models.

By doing so, we hope to extend the empowering leadership literature in two important ways. First, by demonstrating that teams led by an empowering leader achieve greater long-term performance improvement, but at the cost of initial performance delays, we help resolve ambiguity about the benefits of each leadership type through explicating the tradeoffs and boundaries of empowering leadership in teams. Second, by identifying key emergent states and processes within teams that result from empowering leadership and convey its influence into future performance, we shed light on the underlying question of "why" the initial performance costs of empowering leadership may be worthwhile in the long run. 
Apart from its contributions to the empowering leadership literature, this study also extends other extant theories of leadership. In particular, the prescription of empowering or directive leadership based on follower readiness has been a central tenet of situational leadership theories (SLT) (e.g., Hersey \& Blanchard, 1969, 1982; Vroom \& Jago, 1988). For example, Hersey \& Blanchard (1982) highlight follower attributes such as emotional maturity or "readiness" to be empowered, which indicate the extent to which followers are able to share ideas and find motivation in greater responsibility (e.g., Spreitzer, 1995; Chen, Kirkman, Kanfer, Allen, \& Rosen, 2007). However, SLTs have found only limited empirical support (see Thompson \& Vecchio, 2009), in part due to ambiguity as to the nature of follower readiness; a particularly complex consideration when leading collections of individuals in a team context. As we will describe, this study also extends aspects of SLT by providing a more comprehensive way of conceptualizing follower readiness that is specific to the team level and by suggesting limits to the notion that initially directed teams will eventually be ready to receive and respond to empowering leadership.

\section{THEORETICAL BACKGROUND}

Due to its focus on sharing power with employees and emphasizing collaboration (Manz \& Sims, 1987; Arnold et al., 2000), empowering leadership has been touted as particularly suited to meet the needs of leading teams of people (e.g., Kirkman \& Rosen, 1999; Pearce et al., 2003). However, researchers have not always succeeded in finding support for the proposed benefits of empowering leadership on team intermediate and final outcomes (e.g., Mathieu et al., 2006), with a number of studies finding evidence that not empowering leadership, but its counterpart directive leadership - leads to higher performance in teams (e.g., Ensley et al., 2006; Kahai et al., 2004; Yun et al., 2005). Therefore, despite the association of both leadership styles with positive 
team outcomes (e.g., Sagie, Zaidman, Amichai-Hamburger, Te'eni, \& Schwartz, 2002), the relative benefits of empowering and directive leadership in influencing team performance remain unclear (Sosik, Avolio, \& Kahai, 1997; Somech, 2006).

Each style tends to enhance follower performance because both directive and empowering leaders are actively attempting to improve team effectiveness through thoughtful, planned behaviors. Empowering leadership tends to benefit interdependent teams by establishing participative and collaborative norms among members, encouraging them to contribute ideas, decide on optimal courses of action, and take responsibility for team performance. These types of behaviors tend to lead to positive individual and work group outcomes across contexts (e.g., Pearce et al., 2003; Yukl, 1998). For example, Zhang and Bartol (2010) recently provided evidence that empowering leadership enhances employee creativity, through its effects on employee psychological empowerment, intrinsic motivation and creative process engagement. Similarly, Ahearne and his colleagues (2005) found a positive relationship between leader empowering behaviors and followers' job performance, due to increased levels of self-efficacy and adaptability. At the team level, the goal of empowering leadership is to develop a team's capacity to perform autonomously (Manz \& Sims, 1987). Though similar to participatory leadership, which "involves the use of decision procedures intended to allow other people some influence over the leader's decisions" (Yuk1, 1998: 83), empowering leadership requires the leader to invest more trust in their followers by allowing high levels of discretion and decision making authority to pass into their hands.

However, a directive approach, similar to the autocratic leadership style in Vroom and Jago's (1988) decision model and the "tough leadership style" of McIntyre and Salas (1995), focuses on behaviors related to giving detailed directions, expecting subordinates to follow those 
instructions, and making decisions with limited subordinates' inputs. Research suggests that superiors' directiveness can make task accomplishment easier for followers by providing them with specific, role-relevant directions and helping them focus their efforts towards their individual tasks (Fiedler, 1968; Kahai et al., 2004). Additionally, directive leadership helps each individual to be better aware of his/her own role and the availability of role resources (Yukl, 1998), reducing ambiguity about what each person does (Kahai et al., 2004; Pearce et al., 2003) and establishing clear rules for behavior (e.g., Katzenbach \& Smith, 1993). For example, research has shown that directive leadership can lead to improved patient care through the assignment of specific actions for the handling of an emergency situation (Yun et al., 2005). This is in contrast to empowering leadership, in which the higher degree of freedom and discretion granted to team members allows more potential paths towards attaining a goal, potentially decreasing task and role clarity (Evans, 1970; House, 1971).

Situational Leadership Theories (SLT) - conceived as a means of providing practical advice to managers as to when to best apply each different leadership style - are based on the principle that the relative benefits of each leadership type will depend on the competence, maturity, or readiness of the followers (e.g., Goodson, McGee, \& Cashman, 1989; Hersey \& Blanchard, 1969; 1982; Thompson \& Vecchio, 2009). Subordinates with low levels of readiness, such as new employees with limited skills but sufficient motivation, are expected to benefit from a telling, or directive, leadership approach, which entails giving specific instructions to subordinates, as well as monitoring their progress and providing feedback (e.g., Muczyk \& Reimann, 1987; Sims, Faraj, \& Yun, 2009; Yun et al., 2005). On the other hand, when leading followers with higher levels of readiness, with sufficient competence, efficacy and commitment, SLT suggest that participating and delegating styles of leadership should be most effective (e.g., 
Blanchard, 2007). In terms of SLT, empowering leadership falls most closely in line with delegation, though as a practical matter it is difficult to distinguish between delegation and high levels of participatory leadership (see Thompson \& Vecchio, 2009).

Follower readiness was initially defined as "the extent to which a follower has the ability and willingness to accomplish a specific task" (Hersey \& Blanchard, 1988: 174). Addressing criticisms by scholars (see Northouse, 2007), Blanchard (2007) revised the definition with a clearer conceptual typology which combines the follower attributes of competence and commitment to create discrete levels for "developing" versus "developed" followers. However, in teams, though member competence may play an important role in team effectiveness, the "readiness" of teams to respond effectively to empowering leadership is more complex as it is based on the degree to which the team has developed the cognitive, motivational, and behavioral capabilities which are critical for long-term team effectiveness (e.g., Burke et al., 2006). Thus far, SLT has failed to take into account the development of these attributes when conceptualizing readiness of teams.

\section{Team Development}

Teams do not simply manifest collective competence and commitment when needed. Rather, their readiness is temporally bound by the focal stage of their collective development (Kozlowski et al., 1996; Zaccaro et al., 2001), and each leadership approach directly influences how effectively teams mature within critical phases of their development. According to Kozlowski et al.'s (1999) model of team development, the process occurs over four distinct phases during the initial periods of team formation and adaptation. During the first phase, team formation, team members come together to begin the socialization process during which they develop an understanding of the team's collective purpose and start to think of themselves as a 
team. During the second phase, task compilation, individual team members tend to focus their attention on individual task mastery and proficiency, and remain "primarily self-focused on their individual task performance" (Kozlowski et al., 1999: 262). During these initial phases, the role of the leader is primarily felt through socializing the followers into the organization or group and ensuring that they develop the necessary skills to perform their tasks.

In the third phase, role compilation, team members begin to learn to coordinate their performance with other team members through a process of sharing and receiving role information, and clarifying role expectations (Katz \& Kahn, 1978; Graen \& Scandura, 1987). In this phase the influence of active leadership begins to be felt most keenly, as leadership interventions during role compilation are likely to influence the nature and the quality of these interactions (Kozlowski et al., 1999). Specifically, we argue that directive and empowering leadership will differentially affect team development and performance due to their influence on team role compilation processes.

During role compilation, team members should navigate their role interactions, learning about their own and their teammates' responsibilities and capabilities through a series of role identification and clarification behaviors. This allows them to begin using their knowledge of one another to integrate their efforts, resulting in the development of routinized processes and the emergence of shared cognitive structures (e.g., Pearsall, Ellis, \& Bell, 2010). However, team members with directive leaders largely bypass these processes, as the leader gives specific role guidance and provides detailed goals and instructions for each team member, thus actively managing their interactions (e.g., Korsgaard, Schweiger, \& Sapienza, 1995; Sagie, 1996). For example, task execution directions given by a leader are likely to trigger individual member's efforts to perform their role specific task requirements, without the need to learn about their 
teammates' roles in order to ensure their efforts are integrated. The directive leader, therefore, acts as an explicit coordination mechanism for the team, removing the need for the timeconsuming development of learned routines and shared cognitions (Espinosa, Lerch, \& Kraut, 2004). Thus, directive leaders are likely to quickly benefit initial team performance by focusing team members' attention on executing their specific tasks.

Empowering leaders, on the other hand, will tend to first work to establish norms for collaborative decision-making during the role compilation phase. With behaviors emphasizing the open exchange of ideas and suggestions within the team, empowering leaders will attempt to create an atmosphere of increased interaction among team members, which aids individual understanding of "who they interact with to perform the task" (Kozlowski et al., 1999: 266) and the development of shared perceptions and understanding. Therefore, during the role compilation phase, teams led by an empowering leader are likely to focus on developing knowledge of each other and experiencing positive interpersonal interactions, rather than performing (Kozlowski et al., 1999).

Insert Figure 1 about here

Directive leadership during the role compilation phase should therefore be most effective for performance in teams. Teams with a directive leader will be able to sustain their focus on task performance, relying on the explicit guidance provided by their leader. In contrast, because empowering leaders attend to team members' involvement in decision-making and encourage experimentation, learning and collaborative contributions (Arnold et al., 2000; Leana, 1987; Pearce et al., 2003; Srivastava et al., 2006), teams with an empowering leader will initially take longer to effectively perform their tasks. This should enable directively led teams to outperform 
empowered teams during the role compilation phase of team development. Therefore, we hypothesize:

Hypothesis 1. Teams led by a directive leader exhibit higher initial performance than teams led by an empowering leader.

Although directive leaders offer teams an initial performance advantage in the role compilation phase, team performance and adaptability in the fourth phase, team compilation, depend heavily on the role interactions and implicit coordination mechanisms that are expected to emerge during the previous phase (Kozlowski et al., 1999). Through emphasizing team members' involvement in decision making, open communication, and the sharing of ideas and opinions among team members, empowering leaders further enable learning and coordination by creating a climate in which high levels of knowledge exchange are encouraged (Burke et al., 2006; Manz \& Sims, 1987; Srivastava et al., 2006).

Through these processes, the team develops the collective competence, confidence and commitment that make empowering leadership most effective in the team compilation phase. In directed teams, however, the initial performance gains during role compilation come at the price of a reduced capacity for learning and integration of expertise during team compilation. Because directed team members have had less need to engage in role identification behaviors and develop shared cognitions about their roles and the task, they are left less capable of adapting to their task environment and dealing with uncertainty and complexity. The team is, therefore, less able to take advantage of the diverse skills and knowledge of its members and is dependent upon, and limited by, the guidance of the directive leader, who must continue to serve as the sole explicit coordination mechanism for the team. 
Therefore, although directive leaders may be more effective in maximizing the performance of teams in the short term, their actions prevent the team from developing the very processes and emergent states that would allow it to be "ready" for the leader to follow the prescription of SLT to switch to empowering leadership as the team matures. Empowering leaders, on the other hand, despite initial performance delays due to modeling and emphasizing behaviors of frequent interpersonal knowledge and idea exchange (instead of focusing specifically on task performance), should better enable the development of information sharing norms and cognitive structures to prepare teams to make effective decisions and skillfully perform their tasks over the long run. We hypothesize that:

\section{Hypothesis 2. Teams led by an empowering leader exhibit greater performance} improvement in the later, team compilation, phase of development than teams led by a directive leader.

Although research on follower readiness in teams has focused on the individual attributes and perceptions of team members (Goodson et al., 1989; Mathieu, Ahearne, \& Taylor, 2007; Vecchio, 1987), competence and commitment at the team level is far more complex and hinges on the emergence of shared teams states and processes that enable effective task interaction and performance. For teams with high levels of interdependence, and differentiated expertise, long term effective performance and adaptation results from the development of cognitive, motivational and behavioral states and processes which convey leadership onto distal team performance (e.g., Ilgen, Hollenbeck, Johnson, \& Jundt, 2005). Based on Kozlowski et al.’s (1999) model of team development and Burke et al.'s (2006) model of team adaptation, we focus on four critical emergent states and processes which serve both as markers of collective team readiness and mediators of the relative influence of empowering leadership on performance 
improvement: team learning, behavioral coordination, psychological empowerment, and team mental models. Together, we argue that these four states and processes will explain the difference in performance between empowering and directive leadership over the later, team compilation, phase of team development.

Though we extend the definition of team readiness to include these emergent states and processes, this theoretical approach fundamentally differs from Situational Leadership Theories. SLT suggest that team readiness acts as an independent moderator of leadership effectiveness, as the choice of leadership style should be in response to the current readiness of the team (e.g., Thompson \& Vecchio, 2009). However, by focusing on team development as both an outcome of leadership and an enabler of future leadership, we differentiate team readiness as a more complex, shared attribute of the entire team.

\section{Behavioral Processes: Team Learning and Coordination}

During team compilation, team members turn their focus to successful task completion and behavioral adaptation. We suggest that the performance improvement in teams with empowering leaders during team compilation will be due, in part, to the increased ability of such teams to learn and to coordinate their knowledge and actions.

Team learning is "the process by which relatively permanent changes occur in the behavioral potential of the group as a result of group interaction activities through which members acquire, share, and combine knowledge" (Burke et al., 2006: 1190; Edmondson, 1999) and is instrumental in allowing teams to understand and adapt to their environment. This behavioral process is of particular importance for teams with distributed expertise, whose members have to synchronize and leverage diverse skills and abilities to perform complex tasks. As noted previously, teams with empowering leaders will engage in greater levels of role 
identification and discussion during the role compilation phase, leading to a shared understanding of teammates' roles and capabilities. This knowledge acts as a cognitive foundation for information acquisition and exchange during team compilation (Burke et al., 2006), allowing for improved team performance over time.

Similarly, behavioral coordination, which involves "information exchange and mutual adjustment of action in order to align the pace and sequencing of team member contributions" (Marks, Mathieu, \& Zaccaro, 2001: 368) is seen as a critical behavior for interdependent teams as it reflects the smooth integration of skills and knowledge between members. The shared understanding of each other's roles, duties, and capabilities in teams with empowering leaders will allow team members to exchange information and synchronize actions, improving task performance over time.

In contrast, teams with a directive leader, who limits team members' input in decisionmaking and does not consult with subordinates, should be less likely to share the information and knowledge held separately by different team members. Because the directive leader acts as the source for guidance and direction, individual members will tend to focus on their own responsibilities rather than on communicating and sharing with the team (Pearce et al., 2003; Sagie, 1996). Further, a directive leadership style may hamper the development of psychological safety within the team, as the leader does not solicit and encourage input (Edmondson, 1999). Team members in directed teams may, therefore, be much less likely to engage in the experimentation, reflective communication and knowledge codification that typify effective team learning and coordination (Gibson \& Vermeulen, 2003). Without these related behavioral processes, teams with directive leaders are less likely to capitalize on their strong start and, ultimately, less able to improve their performance over time. 
Therefore, we hypothesize:

Hypothesis 3. The greater performance improvement associated with empowering compared to directive leadership during team compilation is partially explained by team learning.

Hypothesis 4. The greater performance improvement associated with empowering compared to directive leadership during team compilation is partially explained by team behavioral coordination.

\section{Motivational State: Psychological Empowerment}

The most direct influence of empowering leadership on team interaction manifests through creating a feeling of psychological empowerment within the team (Chen et al., 2011; Mathieu et al., 2006). Because empowered employees feel more competent and able to influence the team's outcomes, empowerment has consistently been shown to lead to higher levels of employee commitment, innovation, citizenship behaviors and performance (e.g., Seibert et al., 2011; Spreitzer, 2008; Thomas \& Velthouse, 1990; Yuk1, 2010). These feelings of competence and commitment that emerge from empowering leadership likewise make the team particularly ready for empowering leadership in the future. Empowered team members will tend to be motivated by collective ownership of their choices and work, to support and back each other up, and to work towards adaptation and performance improvement during team compilation (e.g., Chen et al., 2007; Kirkman \& Rosen, 1997; Kirkman, Rosen, Tesluk, \& Gibson, 2004).

Therefore we hypothesize that:

Hypothesis 5. The greater performance improvement associated with empowering compared to directive leadership during team compilation is partially explained by team empowerment. 


\section{Cognitive State: Team Mental Models}

Mental models are collective knowledge structures that allow team members to understand and form expectations concerning other team member's responsibilities, needs and behaviors (Mohammed, Klimoski, \& Rentsch, 2000). Because they enable team members to interpret information in a similar manner (Hinsz, Tindale, \& Vollrath, 1997), team mental models have been positively related to team processes such as communication (Marks, Zaccaro, \& Mathieu, 2000), decision-making, and situational awareness (Mathieu, Heffner, Goodwin, Cannon-Bowers, \& Salas, 2005), as well as performance in many situations (e.g., Edwards, Day, Arthur, \& Bell, 2006; Marks et al., 2000).

During the role compilation phase, empowered team members will tend to engage in dyadic exchanges with their teammates regarding the nature and scope of each team member's roles and capabilities, helping them to understand the patterns of behavior and interaction that are emerging within the team. As team members explore the boundaries and extent of each other's expertise and duties, they begin to develop a clear picture of how their unique knowledge, skills, and abilities fit together and how best they can integrate them (Katz \& Kahn, 1978; Kozlowski et al., 1999).

Then, during team compilation, as teams shift their focus more towards task execution, their mental models allow them to revise and refine the flow of work, and to continuously improve performance (Pearsall et al., 2010). Teams with directive leadership, however, have relied on the explicit direction from the leader rather than engaging in time consuming role identification interactions and will have less developed mental models to help integrate their efforts.

Therefore, we hypothesize that: 
Hypothesis 6. The greater performance improvement associated with empowering compared to directive leadership during team compilation is partially explained by team mental model development.

\section{METHODS}

\section{Research Participants}

Participants in this study included 300 senior undergraduate students enrolled in an upper-management course at a major Mid-Atlantic University in the United States. Participants were arrayed in 605 -person teams who engaged in a 3-hour computer simulation task. In exchange for their participation, participants were given extra course credit and were eligible for cash prizes based on their performance ( $\$ 250$ per team).

\section{Task}

Participants were randomly assigned to teams and, with the exception of each team leader, randomly assigned to roles within the team. They then worked collectively to complete tasks within a networked computer simulation - the Leadership Development Simulator (LDS) originally developed for the Squadron Officer School at Maxwell Air Force Base and used to train and evaluate mid-career officers (see Davison, Hollenbeck, Barnes, Sleesman, \& Ilgen, in press). The LDS is a complex task in which teams of four staff members and one leader must manage a large number of resources (48 assets in each round) to discover and interact with targets on a shared task screen over 10 rounds of decision-making. To be successful, team members must collaborate their efforts to achieve certain objectives (such as attacking a large target or verifying intelligence), which, in turn, produce a higher performance score.

Team members and their leader were seated around a table, each in front of a separate computer station, and were able to freely talk with each other throughout the simulation. Each 
team member had a defined role with assigned responsibilities, arranged in a functional hierarchical structure containing staff members (the four players) and a formal leader. Each staff member was either in charge of Operation or Intelligence assets that could be used to gather and employ information about enemy targets (described below).

Teams were in charge of assessing and integrating multiple sources of information in the process of finding and engaging targets on the task screen, which include both threats and opportunities. Opportunities manifested as enemy vehicles and bases that they could destroy to gain offensive points. Threats manifested on the simulation screen as enemy vehicles and launchers that were capable of destroying team members' assets, costing the team defensive points. Threats were commonly placed with opportunities to protect them from attack. The team's goal was to maximize their performance by identifying and destroying enemy threats and opportunities while avoiding having their own assets destroyed by enemy threats.

Team member roles. Teams were functionally structured with defined, specialized roles and expertise, and were responsible for fulfilling the same role throughout the entire simulation. Except for the leader, the other four team members were randomly assigned to one of four roles in either Operations or Intelligence positions. The two team members who primarily gathered information about the environment were labeled as "Intelligence" team members, and the two members who engaged threats and opportunities to score points and protect bases were labeled as “Operations" team members.

Members in the Intelligence positions were assigned to one of two Intelligence roles Signals or Human intelligence - and each managed 2 types of discrete information assets (8 assets of each type for a total of 16 per player and 32 per team) that could be placed anywhere on the game grid each round to identify threats and opportunities. Each intelligence asset was 
effective in a different region of the environment and could be deployed to a single location on the screen to gather probabilistic information regarding that area of the environment. These assets could not be lost to enemy threats; however, they were only accurate ( $95 \%$ accurate) in one area of the simulation environment, known as the "sweet spot." The "sweet spot" could be located in the upper half, the lower half or the middle of the screen and each of the 4 types of Intelligence assets were only accurate in this specific portion of the task screen. In the rest of the screen, assets would either give no information or, occasionally, false information. Therefore, identifying the "sweet spot" for each type of asset was a critical responsibility of the entire team. In contrast, Operations team members had four different types of assets: Strike, Escort, Refuel, and Information. Strike assets had the capability of capitalizing on opportunities. Escort assets had the capability of destroying threats. Refuel assets enabled other assets to reach distant portions of the environment. Information assets gathered information from areas larger than the areas investigated by Intelligence assets. In contrast to Intelligence assets, the information that was gathered by Information assets was always completely accurate (100\% accurate). These assets were controlled by the 2 Operation members - Offensive and Support. The Offensive operation member controlled 4 strike and 4 escort assets and was responsible for utilizing these assets in the entire task screen. The Support member controlled 4 refuel and 4 information assets and was responsible for utilizing these assets to support strike and escort vehicles, or coordinate grid searches with intelligence members, respectively.

In addition to the four staff members, the team had an assigned leader who could approve or change the decisions made by the Offensive and Intelligence team members.

Simulation environment. The environment in the LDS consisted of a grid, 16 rows (116) by 16 columns (A-P), totaling 256 squares. At the start of the simulation, teams were 
presented with a blank grid. However, as shown in Figure 2, hidden throughout the grid were threats and opportunities, which could be either small or large, and either fixed or mobile. Threats attacked assets and bases, costing the team points. Opportunities could be destroyed by Strike assets, gaining the team points. Teams needed a single asset to engage a small target, but they needed two assets to engage large targets. Fixed targets remained in the same square throughout the entire simulation, while mobile targets moved around the grid.

Insert Figure 2 about here

Teams engaged in the simulation through a series of "rounds" or decision-making periods. During the first 3 minutes of each round, team members deployed their assets on the simulation grid. Next, the team leader had one and a half minutes to review the team decisions and make any desired changes to the asset allocation. Then, teams viewed the results of their choices, seeing what threats and opportunities their assets had located and engaged, and had 2 minutes to analyze this feedback and make decisions for the next round. In total, each team performed the task for 10 rounds.

\section{Procedure}

About 3-4 weeks before the experimental session (upon signing up to participate in the study), participants completed an on-line questionnaire that assessed their natural leadership tendencies, described in the Leadership manipulation section below. After team members were randomly assigned to teams, the leader of each team was selected for training based on his or her natural inclination to behave in a directive versus empowering way, depending on condition (as described below). Selected team leaders were trained to exhibit desired leadership behaviors in isolation from the rest of the team, immediately before the start of the experiment. 
Upon arriving at the laboratory, participants in staff positions were randomly assigned to Operations or Intelligence roles within the team, after which participants completed a pre-task survey (capturing the control variables) and were introduced to the other team members and the purpose of the team task. Next, the entire team was trained with a 30 min pre-recorded presentation on how to operate the simulation, with the team introduction and the training phases mirroring the team formation and task compilation phases of Kozlowski et al.'s (1999) framework. During these early team development phases members were asked to focus on understanding the team task (the team's collective purpose), mastering their individual tasks, and developing the skills necessary for their task completion.

Following the whole team training, to reinforce the manipulation, leaders were asked to make a statement to the team and use pre-scripted comments consistent with the respective leadership style (see Appendix). Then, participants performed 5 rounds of the task, after which the simulation was paused. This 5-round period coincides with the role compilation phase of team development, during which team members predominantly engage in role identification behaviors in an attempt to maximize their role knowledge. At this point, leaders were again reminded about the pre-scripted comments available for their leadership style. Teams then performed the five additional rounds of the task, which mirror the team compilation phase, during which team members were expected to integrate their efforts in order to maximize performance. After the end of the simulation participants completed a short survey measuring their perceptions of the leader and psychological empowerment, as well as the team mental model measure. Then subjects were debriefed and thanked for their participation. 


\section{Measures and Manipulations}

Leadership manipulation. In this study we manipulated leadership using a two-step approach advocated by Durham and her colleagues (1997), which utilizes both selection and training to maximize the effectiveness of leadership manipulation. More specifically, the leader was chosen based on his/her personal predisposition to behave in an empowering or directive way and then additionally trained to exhibit the desired leadership behavior.

As noted above, the leader for each experimental team was selected based on results from an online questionnaire administered prior to subjects reporting to the experimental venue. We used the 10-item Directive Leader Scale (Durham et al., 1997), which was adapted from Cox and Sims (1996), to select a "directive" leader. Participants were asked to indicate on a 7-point Likert type scale $(1=$ extremely uncomfortable, and $7=$ extremely comfortable $)$ the extent to which they would feel comfortable performing directive-leader behaviors while working in a group, such as "taking charge of a group," "giving instructions to group members," and "specifying others' roles in a group task."

The highest scoring individual on the directive leadership inclination was chosen for the role of the directive leader in teams randomly assigned to the Directive Leadership condition. In order to maximize the difference (and the influence of the manipulation), a similarly constructed survey was used to select the empowering leader in the "empowered" teams - participants filled in a survey asking to what extent they felt comfortable performing empowering behaviors. The items were adapted from the Empowering Leadership Questionnaire (ELQ), developed by Arnold and his colleagues (2000), and participants responded by indicating on a 7- point Likert type scale $(1=$ extremely uncomfortable and $7=$ extremely comfortable $)$ the extent to which they would feel comfortable, while working in a group, performing empowering leader behaviors 
such as "encourage group members to assume responsibilities on their own," "advise group members to exchange information with one another," and "listen to and consider ideas and suggestions of group members.” The highest scoring individual on the ELQ in a team randomly assigned to the Empowering Leadership condition was selected for the role of the empowering leader. Team leaders were not informed the reason for their selection.

The selected leaders were trained on site, in the simulation lab, immediately before each experiment. Training has been shown to have an impact on leader actions (e.g., Towler, 2003) and to increase the use of desired leader behaviors (e.g., Barling, Weber, \& Kelloway, 1996; Towler, 2003), even when the manipulation was only five-minutes long (e.g., Manz \& Sims, 1986). In this study, team leaders received 30 minutes of training, the composition of which depended on their experimental condition. Directive leaders were first exposed to a 10-minute verbal presentation, which explained and detailed what kind of behaviors they were expected to exhibit. Then they were shown a short movie clip - adapted from Apollo 13, emphasizing the desired directive leader behaviors, followed by a 10 minute role play simulation which again emphasized the desired behaviors. For the last $5 \mathrm{~min}$ of the training, directive leaders were also trained and asked to develop a specific game plan without input from team members and to ask team members to carry out the proposed game plan (Yun et al., 2005).

The selected Empowering leaders were exposed to a similar 30 min training that included: a 10-minute verbal presentation, which explained and emphasized the kind of behaviors the leader was expected to exhibit during the simulation; a short movie clip -also adapted from Apollo 13, this time emphasizing empowering leadership; and a 10-minute roleplaying exercise to strengthen the modeled behaviors. For the last $5 \mathrm{~min}$ of the training 
empowering leaders were asked to develop a plan to include all the team members in setting team performance goals, exchanging ideas and information with one another.

To aid leaders in acting in a directive or empowering manner they were given a "cheat sheet" with a list of key verbal prompters that were suggested for use during interaction with the team throughout the simulation. The phrases listed on this "cheat sheet" (shown in the Appendix), reflect general rules of the simulation rather than specific, expertise based comments and served simply to reinforce the manipulation. Finally, the leaders were given a statement to read before the beginning of the experiment with the text of the statement emphasizing directive or empowering leader behaviors.

Team performance. Team performance was calculated as the sum of team's offensive (points gained) and defensive points (points lost) during each round of the simulation and reflected the team's primary objective to maximize its score. Teams received points each time they engaged an opportunity or neutralized a threat and lost points each time one of their assets was destroyed by a threat or a threat reached the team base. Specifically, teams scored 4 points for capitalizing on a small opportunity and 16 points for capitalizing on a large opportunity, they scored 2 points for destroying a small threat and 4 points for destroying a large threat, and teams lost 8 points for each asset destroyed by a threat and each time a mobile threat reached a base.

Team learning. Team learning was assessed by the number of intelligence assets sent to the correct "sweet spots" (described above) during each round of the simulation. This measure was based on the degree to which the team identified the areas in which their intelligence assets were accurate, which required team members' joint experimentation and reflective communication about the results of the experimentation (Gibson \& Vermeulen, 2003). At the beginning of the simulation team members were unaware in which part of the grid each type of 
intelligence asset would accurately identify threats and opportunities. Without accurate information, team members would be unable to engage enemy opportunities and threats, making sweet spot identification critical for team success. To learn the sweet spot areas for each type of asset, team members in all roles had to exchange information received from their own assets, engage in experimentation and share their mistakes and successes, integrate the placement of their assets to "double source" a grid square and verify which assets were effective there, and to consolidate the information received from their assets with the rest of the team. Once teams learned where intelligence assets were accurate, they were able to send them to the grids on the task screen where they would be most effective - the sweet spots - to identify targets and opportunities for scoring. Therefore, the number of intelligence assets sent to the sweet spots indicated the effective transfer and application of team learning in each round.

Behavioral coordination. Our measure of behavioral coordination focuses on the alignment of team member actions towards their interdependent task, as described by Marks et al. (2001). Specifically, we measured the number of times during each round that strike and escort assets received refueling support from the operations support role to investigate and destroy enemy opportunities and threats identified by intelligence. All missions sent to the "north," or top half of the game grid, required refueling support, without which the tasked assets would run out of fuel and be destroyed. In order for a strike or escort mission to survive a trip to the "north," multiple team members must agree on how best to allocate their respective resources and then simultaneously commit them to the same game grid square.

Team empowerment. Team empowerment describes a team's collective sense of authority and responsibility to control their work and was measured with a 6-item measurement instrument adapted from Mathieu and colleagues (2006) $(\alpha=.87)$. Each team member indicated 
on a 5-point Likert-type scale $(1=$ Strongly Disagree and $5=$ Strongly Agree $)$ the extent to which they agree or disagree with the following exemplary statements: "In our team members are responsible for deciding how to achieve our goals," "My team is empowered to change our work processes in order to improve our performance" or "In our team members have a great deal of freedom in deciding how we will do our work." We used James, Demaree, and Wolf's (1984) $r_{\mathrm{wg}}$ agreement index, to justify aggregating individual members' response to the team level (mean $\mathrm{r}_{\mathrm{wg}}=.91$ ). In addition we calculated and report here the intraclass correlations (ICCs), which represent whether measures are sufficiently reliable to model effects at the team level. ICC(1), indicating the reliability of a single rating of the team construct equaled .49 , and ICC(2), which represents the reliability of the average (mean) team members' responses, equaled .79. Thus, reliability statistics, coupled with our theoretical reasoning, provided support for reliable teamlevel effects and we proceeded with aggregating the individual members' scores to arrive to a single score for each team (Bliese, 2000).

Team mental models. To assess team mental model development, we adapted Marks et al.'s (2000) concept mapping technique that was specifically designed for tasks such as this (e.g., Ellis, 2006). Following the experimental task, team members were given a task scenario accompanied by eight blank spaces (two per team member) that needed to be filled with one of eight concepts that represented different aspects of team member roles and capabilities. Team members completed the maps by placing concepts that best represented the actions of each team member on the diagram. These mental maps reflect the models held by team members throughout the performance session and were constructed specifically for this study based on team members' roles during the experimental task. For example, for the Operations Support role, 
team members would need to accurately identify that they possessed refueling and information assets and when they would deploy them.

To arrive at the team-level mental models score we used each team member's individual concept map and compared it to each of the other team members' concept maps, dividing the number of matching responses by the total number of possible dyadic matches for a total team mental model similarity score ranging between 0 and 6 .

Control variables. In this study we controlled for two team ability and experience factors which may play a role in team performance and learning: team cognitive ability, in terms of average GPA per team (e.g., LePine, 2003), and team members' degree of computer-game experience, which was measured with a 3-item measure $(\alpha=.80)$ which asked participants to indicate their level of computer game experience (e.g., "How skilled are you in playing computer games?" $1=$ Unskilled and $5=$ Very Skilled). The individual scores were averaged to arrive at a team-level computer game-experience score.

\section{RESULTS}

Manipulation checks. To ensure that leader behaviors were consistent with their experimental condition, we measured the extent to which team members perceived that their leader behaved in an empowering or a directive manner with two 5-item instruments, adapted from Pearce et al. (2003). The instruments were administered to participants after the end of the simulation in order to avoid biasing team members' perceptions of the leader during the simulation execution (Durham et al., 1997). One of the instruments measured perceived directive leadership and the other measured perceived empowering leadership. For empowering leadership, a sample item read "The team leader gives the team autonomy and freedom of action," and for directive leadership an example item read "The team leader defines tasks and 
responsibilities for group members." Both measures used 5-point Likert type scales $(1=$ Strongly Disagree and 5 = Strongly Agree). The mean $\mathrm{r}_{\mathrm{wg}}$ for perceived directive leadership was .77 and each workgroup $r_{w g}$ value exceeded the .70 , which is commonly used as a cutoff to justify aggregation of individual-level measures to the group level (Klein \& Kozlowski, 2000). Similarly, the mean $r_{w g}$ for perceived empowering leadership was .84 , exceeding the .70 value commonly used as a convention cutoff point. Intraclass aggregation statistics for perceived directive leadership were as follows: $\operatorname{ICC}(1)=.22, \operatorname{ICC}(2)=.63$; and for perceived empowering leadership: $\operatorname{ICC}(1)=.28 ; \operatorname{ICC}(2)=.68$, justifying aggregation (Bliese, 2000; James, 1982; Kirkman et al., 2004; Mathieu et al., 2006) to the team level.

Results indicated that the participants in the Directive condition perceived their leader to be significantly more directive $(M=3.77 ; S D=.49)$ than those in the Empowering condition $(M$ $=3.12 ; S D=.45) ; \mathrm{t}(58)=5.35, \mathrm{p}<.01$. Similarly, teams in the Empowering condition viewed their leaders as more empowering $(M=3.96 ; S D=.37)$ than teams in the Directive condition $(M$ $=3.05 ; S D=.52) ; \mathrm{t}(58)=7.81, \mathrm{p}<.01$. Together, these results provide support for the effectiveness of the two leadership manipulations.

Measurement timing. To test whether the timing of our measures coincided with the theorized phases of team development, we focused on the degree to which teams engaged in risky, experimental behaviors which are more common in earlier phases - specifically, the number of unescorted missions. When an operations asset is sent on a mission, it may be destroyed by enemy threats unless accompanied by escort assets. However, using escorts limits the number of possible missions in each round, making the number of unescorted missions a proxy for risk taking by the team. Results show that the number of unescorted missions in the role compilation phase (rounds $1-5 ; \mathrm{M}=2.40, \mathrm{SD}=1.60$ ) were significantly higher than in the 
team compilation phase (rounds $6-10 ; \mathrm{M}=1.07, \mathrm{SD}=1.32 ; \mathrm{t}(294)=8.24, \mathrm{p}<.01$ ), suggesting that teams in the team compilation phase had shifted their focus away from experimentation towards the routines and performance improvement associated with team compilation.

\section{Data Analyses}

Consistent with the nature of our hypotheses we used three different statistical analyses. First, we used a two sample t-test to test our first hypothesis (Hypothesis 1), examining the difference in the overall level of team performance in the initial (role compilation) phase of team interaction between the two conditions of directed and empowered teams respectively.

To test the nature of the leadership-time interaction and performance improvement hypotheses (Hypotheses $2-4$ ) we estimated random coefficient growth models (RCM) following the six-step model estimation procedure of Bliese and Ployhart (2002), entering leadership as a dichotomous Level 2 variable (Empowering leadership $=1$ and Directive leadership $=0$ ) and the team performance scores at each round as a Level 1 outcome. All analyses were conducted using the Nonlinear and Linear Mixed Effects package (nlme) in the statistical software R version 2.14.0. First, we started with specifying the Level 1 model (steps 1 through 4: see Bliese and Ployhart, 2002, for a detailed description of the procedure) in which performance scores of the teams were examined for growth over time. Having correctly specified the Level 1 model, we proceeded with examining the Level 2 model (steps 5 and 6) in which leadership is entered as a time-invariant team level variable and the cross-level interaction between time and leadership is used to estimate the extent to which leadership accounts for between-team differences in slope parameters for the time-performance relationship (Hypothesis 2). Repeating the steps outlined above we again used RCM to examine the mediating roles of team learning (Hypothesis 3) and team behavioral coordination (Hypothesis 4) on performance 
improvement during the team compilation phase of team development (rounds 6 through 10) following the recommendations of MacKinnon and colleagues (2007).

Finally, to test our fifth and sixth hypothesis we used generalized least square (GLS) regression analysis to regress the team performance score for each performance round of the team compilation phase on the relevant variable (independent variable and mediators) and control variables. The use of GLS allowed us to use the one-time measures of team empowerment and team mental models (which made it impossible to utilize RCM for Hypotheses 5-6) at the same time accounting for the data heteroskedasticity and correlations among the dependent variable multi-time longitudinal observations. Having established the relevant regression coefficients we then constructed bootstrapped confidence intervals to estimate the strength of the indirect path (Preacher, Rucker, \& Hayes, 2007).

\section{Hypothesis Testing}

The summary of means, standard deviations and intercorrelations among the study variables of interest is provided in Table 1 . None of the control variables were significantly correlated with team performance; however, in order to increase the robustness of our results, we controlled for them in the subsequent analyses.

Insert Table 1 about here

Hypothesis 1. Our first hypothesis proposed that teams led by a directive leader would exhibit higher initial performance than teams led by an empowering leader. Results of a twosample t-test comparing the performance results of directive versus empowering teams during the role compilation phase of team development (Rounds 1-5) indicated that directed teams $(M$ 
$=7.33 ; \mathrm{SD}=14.30)$ significantly outperformed empowered teams $(M=-3.52 ; \mathrm{SD}=19.01) ; \mathrm{t}_{(58)}$

$=2.50, \mathrm{p}<.05$. Therefore, our first hypothesis was supported.

Hypothesis 2. Our second hypothesis proposed that teams led by an empowering leader would exhibit greater performance improvement in the team compilation phase than teams led by a directive leader. In order to test this hypothesis we built and tested a random coefficient growth model following the six step procedure outlined in our data analyses section. At steps 1 through 3 we specified our Level 1 Model and found that (as expected) there was a positive and significant linear trend for the influence of time on team performance $(\gamma=1.62, \mathrm{p}<.01)$. Further, the significant slope variation among teams (as suggested by a log-likelihood comparison of the model with fixed versus random slope effects: $\operatorname{LL}(2)=211.61, \mathrm{p}<.01)$ indicated that the model with the random slopes fitted the data significantly better. Modeling heteroskedasticity as an exponent of the (time) covariate at Step 4 additionally improved the fit of our Level 1 Model $(\operatorname{LL}(2)=57.79, \mathrm{p}<.01)$

In steps 5 and 6 of the RCM procedure we specified the Level 2 Model and, as shown in Table 2, Final Level 2 Model, the interaction term involving leadership and time was positive and significant $(\gamma=.34, \mathrm{p}<.05)$, providing support for Hypothesis 2 . In order to better understand the cross-level longitudinal influence of leadership (specifically, empowering leadership, which was coded as 1) we plotted the interaction in Figure 3.

Insert Table 2 about here

Insert Figure 3 about here 
As shown in Figure 3, teams led by an empowering leader exhibited lower initial performance, and greater performance improvement, than teams led by a directive leader, supporting both Hypotheses 1 and 2. We then tested the mediating role of 4 behavioral, cognitive and motivational processes and states in explaining the difference in performance between teams with empowering and directive leaders during team compilation.

Hypotheses 3 and 4. Hypotheses 3 and 4 proposed that the difference in performance between empowering and directive leadership during the team compilation phase of team development would be partially explained by team learning and behavioral coordination, respectively. Due to their nature, these hypotheses should be treated as mediated longitudinal moderation (Muller, Judd, \& Yzerbyt, 2005). To support these hypotheses we had to demonstrate that the two mediators - team learning and behavioral coordination - were significantly related to team performance improvement while simultaneously leading to a drop in the significance of the interaction term, involving time and leadership. Such a result would indicate that the differential influence of empowering and directive leadership over time became less significant when team learning and team behavioral coordination were included in the equation (see MacKinnon et al., 2007, for a detailed explanation of the procedure).

In testing the first step of the mediated moderation hypothesis we found that leadership ( $\gamma$ $=9.72, \mathrm{p}<.05)$ as well as the interaction between time and leadership $(\gamma=1.19, \mathrm{p}<.05)$ were positively and significantly related to team learning during the team compilation phase (Hypothesis 3). Similarly, leadership $(\gamma=5.69, \mathrm{p}<.05)$ and the interaction between time and leadership $(\gamma=.77, \mathrm{p}<.05)$ were significantly related to team behavioral coordination during team compilation (Hypothesis 4). Then, in the next step of our hypothesis testing, all of the independent variables (including the two mediator variables) were included in the RCM equation 
for team performance. Table 3 presents the results of this step. As shown in Table 3, the coefficient for the interaction term involving time and leadership failed to reach significance $(\gamma=$ $1.24, \mathrm{~ns})$, whereas both team learning behaviors $(\gamma=.39, \mathrm{p}<.05)$ and behavioral coordination $(\gamma$ $=1.26, \mathrm{p}<.01)$ were positively and significantly related to team performance over time.

In order to estimate the strength of the indirect effect we followed the recommendation of Bauer, Preacher, \& Gil (2006) and calculated the $95 \%$ confidence interval of the indirect effect by employing Monte Carlo Method for Assessing Mediation (MCMAM). The calculated confidence interval estimating the strength of the team learning indirect effect $[\mathrm{CI}=.03 ; 1.07]$ did not include zero, indicating a significant indirect effect through team learning (H3). The confidence interval around the indirect effect of team behavioral coordination $[\mathrm{CI}=.05 ; 2.24]$ also excluded zero, indicating that behavioral coordination accounted for significant variance in team performance improvement (H4). Cumulatively these findings supported both Hypothesis 3 and Hypothesis 4.

Insert Table 3 and Table 4 about here

Hypotheses 5 and 6. Hypothesis 5 proposed that the greater performance improvement for empowered team (compared to directed teams) in the team compilation phase of team development would be partially explained by team empowerment. Hypothesis 6 proposed that team mental models would also serve as a simultaneous mediator to explain the greater performance improvement of empowered teams. As noted in the Methods section we used GLS regression to account for the mediating role of team empowerment (Hypothesis 5) and mental models (Hypothesis 6) in the team compilation phase of development (Rounds 6-10). Our results 
supported both Hypothesis 5 and Hypothesis 6. Specifically, consistent with Shrout and Bolger (2002) recommendations, the leadership condition was positively and significantly related to each of the mediators $(\beta=.12, p<.05$ : Table 4 , Model 1 and $\beta=.53, p<.01$ : Table 4 , Model 2 respectively) providing support for our reasoning that leadership did explain variability in team motivational (team empowerment) and cognitive (team mental models) states. Then, in the final step of the mediation testing, team empowerment $(\beta=26.14, p<.01$ : Table 4 , Model 3$)$ was significantly and positively related to team performance, while the interaction term involving time and leadership failed to reach significance. The $95 \%$ bootstrapped confidence interval estimating the strength of the indirect effect excluded zero $[\mathrm{CI}=.95 ; 5.95]$. Together, these findings provided support for Hypothesis 5.

Team mental models development was also positively and significantly related to team performance when included in the estimation of the full mediation model (together with team empowerment, leadership condition, and the interaction term between time and leadership condition): $\beta=2.26, p<.05$. The interaction term between time and leadership failed to reach significance in the full mediation model and the confidence interval estimating the strength of the indirect effect excluded zero $[\mathrm{CI}=.17 ; 2.51]$, supporting Hypothesis 6 .

\section{DISCUSSION}

Recent theoretical developments and organizational trends have highlighted the benefits of empowering leadership for individuals and teams (Chen et al., 2011; Srivastava et al., 2006; Zhang et al., 2010). However, research examining the effectiveness of empowering leadership on team performance has been far from conclusive, with a number of studies finding evidence that directive leadership may actually lead to higher performance, especially in the cases of action and project teams (Ensley et al., 2006; Yun et al., 2005). 
To help resolve this debate, and to extend existing theory to clarify some of the theoretical ambiguity regarding their relative benefits, we investigated the influence of empowering and directive leadership on the performance of newly formed teams over time. Our results indicated that although teams with directive leaders started performing well more quickly, their performance plateaued, whereas the emergent cognitions and improved learning and coordination capabilities of empowered teams allowed them to improve over time. These findings offer a number of theoretical and practical implications.

\section{Theoretical Implications}

Departing from previous research that has predominantly considered leadership types in isolation (e.g., Mathieu et al., 2006; Srivastava et al., 2006), we directly compare two distinct leadership types in order to resolve conflicting results in the literature about the effectiveness of these leadership approaches on team performance. Doing so provides insight into both when and why empowering and directive leadership approaches are most effective in teams, and contributes to debate as to the limits and benefits of empowerment (e.g., Cotton, Vollrath, Lengnick-Hall, \& Froggatt, 1990; Leana, Locke, \& Schweiger, 1990; Spreitzer, 1995; Wagner, 1994).

Conceptually, our findings confirm the existing notion about the positive influence of empowering leadership found in the literature for individual performance (e.g., Ahearne et al., 2005; Zhang et al., 2010) and in long-standing, top management teams (Srivastava et al., 2006) and extend them to account for the specifics of the action and project teams which undergo team development before reaching their full potential (Kozlowski et al., 1999). However, by demonstrating that empowering leadership comes at an initial performance cost, we highlight an important boundary condition to empowering styles that may help explain some of the 
inconsistent, or weaker, effects on performance found in the literature (e.g., Mathieu et al., 2006).

We also extend the empowering leadership literature to consider the critical role of team developmental phases, demonstrating that the influence of leadership manifests directly through emergent team processes and states. Empowering leaders encourage team members to engage in role exchanges and collective investigation in the early role compilation phase of development, in which they learn about the task environment and each other's areas of expertise to develop team mental models of how to integrate their efforts, gain collective efficacy and commitment through psychological empowerment, and foster routines to coordinate their behaviors (Kozlowski et al., 1999; Pearsall et al., 2010). This time-consuming process puts them at a performance deficit compared to teams with directive leaders, who immediately focus on task performance, relying on their leader to provide explicit coordination within the team. However, teams with directive leaders are eventually "overtaken" by empowered teams as they enter the team compilation phase of development and adaptation, in which teams increasingly rely on their routinized processes and shared cognitions to smoothly coordinate their efforts and knowledge, and continuously improve their performance (e.g., Edwards et al., 2006; Marks et al., 2000).

By taking a longitudinal approach to examining these two leadership styles, we provide a more nuanced explanation for previous findings. A simple cross-sectional analysis of the final performance within each condition would have revealed no significant difference between styles at that single point in time. Similarly, a mid-point evaluation would have suggested that directive leadership is much more effective than empowering. However, both approaches would have missed the complex relationship between leadership and team member interactions that plays out over time and may explain why previous work has been equivocal. These findings, therefore, 
help extend both the leadership and team development literatures, and provide a framework for understanding when and at what stages of team development directing team members may positively impact team performance.

Finally, we extend Situational Leadership Theory by identifying four critical motivational, cognitive and behavioral markers of team development and readiness that help explain why the influence of empowering leadership in the role compilation phase promotes higher continual performance improvement in the team compilation phase of development. The current conceptualization of follower readiness tends to focus on the maturity, commitment and skill level of the individual followers, but neglects the critical team processes and emergent states that allow empowering leadership to be effective at the team level. Teams with diverse expertise, working interdependently on complex tasks, require an investment in time and leader support to develop the behavioral processes, such as learning and coordination, as well as the shared cognitive understanding to effectively perform and adapt. This investment, paid through the empowerment of team members during role compilation, takes longer to pay off, but is critical for such teams' long-term success. However, because the emergence of these states and processes is limited by directive leaders, these results also raise questions about the central tenet of SLT that teams with an initial directive leader will eventually become ready for that leader to switch to an empowering style.

\section{Managerial Implications}

These findings also have number of implications for managers placed in charge of teams. First, the time sensitive nature of the benefits of each leadership style provides a framework for managers to follow depending on the timeline of their task or project. For teams on short-term or emergent engagements, as well as teams facing emergency situations (e.g., surgical, police, 
military, flight crews), a directive style may be most appropriate as teams must be able to immediately perform at a high level and cannot afford the performance delays and learning errors associated with empowered teams (e.g., Bobic \& Davis, 2003; Sims et al., 2009; Yun et al., 2005). However, when teams have an extended timeline, such as project or software development teams, or must be able to adapt to complex and changing environments over time, an initial and continuing empowering leadership style may be most appropriate as it encourages the development of shared cognitive structures, routines for learning and coordination, and feelings of collective competence and commitment during the role compilation phase that set the stage for higher long term performance.

However, it is important that managers do not misinterpret these findings to conclude that a directive leadership style is beneficial early, but that one should switch to an empowering style as teams progress to the team compilation phase of development. Although there may be some advantage to employing a combination of the two leadership approaches (e.g., Gratton \& Erickson, 2007), our results suggest that the benefits of empowering leadership in teams tended to manifest because team members initially engaged in role identification and learning processes during the role compilation phase. Empowered teams, therefore, may not able to reap the benefits of improved performance over time without first suffering the initial performance delays.

Finally, due to the critical role of team learning in empowered teams, managers who seek to adopt an empowering leadership style should also focus their efforts on facilitating a team learning and information sharing orientation (e.g., Burke et al., 2006; Bunderson \& Sutcliffe, 2003). They can do so by encouraging risk taking and experimentation, and the development of a psychologically safe environment (e.g., Edmondson, 1999; Edmondson, Bohmer, \& Pisano, 
2001). Recently, Walumbwa and Schaubroeck (2009) found that leaders who engaged in active, ethical leadership created feelings of psychological safety in their followers, leading to higher levels of voice behavior. This suggests that empowering leaders who genuinely value the inputs of their team members and allow them to fail without repercussion may be best able to cultivate an autonomous learning environment. However, it also raises the possibility that leaders who attempt to "fake" an empowering manner, without any real willingness to sacrifice their own authority, may be thought of as disingenuous and the team may never develop the levels of safety so necessary for psychological empowerment and learning.

\section{Limitations and Directions for Future Research}

This study also has a number of limitations. First, the scope of this study was restricted to relatively short-term teams, which were put together for a specific complex task (Sundstrom, 1999). In addition, the teams in this study enjoyed very high levels of interdependence, which, coupled with a comparatively short duration life cycle, may limit the generalizability of our findings to action and project teams. Although these types of teams are increasingly common in organizations, it is possible that the relationships we examined in this study may evolve differently in long-standing teams or in teams with lower levels of interdependence. For example, in teams with low levels of task interdependence the role specification and task assignments related to directive leadership may lead to even greater performance benefits, whereas the performance improvements associated with empowering leadership may never fully materialize. Similarly, creative teams or teams facing greater task ambiguity may not develop or benefit from the shared cognitions and enhanced coordination associated with empowering leadership. However, those types of teams may still see higher levels of creative engagement and performance from feelings of engagement and commitment (Zhang \& Bartol, 2010). 
Second, because this study was conducted in a laboratory, research would benefit from establishing the external validity of our proposed relationships in a field setting. Although controlled settings offer the clear advantage of manipulating variables of interest and reducing causality concerns, certain features of our task might have biased our results. For example, teams in this study operated under a functional structure with distributed expertise, which requires high levels of information and knowledge exchange for the team to be successful. A different task, employing a divisional or parallel team structure, for example, may have required less knowledge exchange among team members, activating different team learning processes and behaviors (Ilgen et al., 2005).

Also, these teams were assigned new, inexperienced leaders without any particular technical expertise. Although such situations may be common in many organizations (e.g., recent MBAs are often assigned to lead a product development team without having worked their way up through their new organization) we acknowledge that our leader selection may not mirror the leader assignment process in organizations in which leaders are assigned to projects based on their technical skills and/or expertise. It may be that high levels of skill and experience are particularly beneficial for directive leaders while less important for empowering ones (e.g., Vroom \& Jago, 1988), and the relative trajectories of performance for each leadership style in this study may be moderated by characteristics of the leaders as well as the team. Further investigation of the important role of leader ability in team development would be valuable for extending our results and bounding the external validity of our findings.

There may also be some ambiguity as to the long-term implications of our longitudinal results. Although the performance of empowered teams increased steadily during the team compilation phase, while the performance of teams with directive leaders was flatter, it is 
impossible to state definitively how long these trajectories would have continued. Although there is no reason to believe that the performance of teams with directive leaders would begin to improve in future rounds of task execution, it is not clear how much longer teams with empowering leaders would have continued to learn and improve and it may be that empowering teams performance would have begun to plateau shortly after our study ended.

Further, while our results suggest that teams with initial directive leaders will not develop the "readiness" to be empowered, we have little idea of whether initially empowered teams will benefit from future directive leadership. It may be that teams have asymmetric capacities to adapt to new leaders, much the way they differentially respond to changes in structure (e.g., Moon et al., 2004) or rewards (e.g., Johnson et al., 2006). Further research focused on longer term teams with multiple types of leaders over time would help to resolve the extent of the influence of leadership on team development and performance.

Finally, although we examined the influence of leadership over multiple phases of team development as described by Kozlowski et al. (1999), we cannot definitively identify the beginning or end of each phase of team development. Teams develop through a "continuous series of phases, with partial overlap at transitions" (Kozlowski et al., 1999: 248) and the timing of our measures was intended to capture the essence of that transition, rather than to present a conclusive, discrete demarcation of each phase. Therefore, it would be valuable for future research to examine the longitudinal benefits of empowering leadership over a longer-term task, or series of tasks, where the duration of each developmental phase varies. 


\section{REFERENCES}

Ahearne, M., Mathieu, J., \& Rapp, A. 2005. To empower or not to empower your sales force? An empirical examination of the influence of leadership empowerment behavior on customer satisfaction and performance. Journal of Applied Psychology, 90: 945-955.

Arnold, J. A., Arad, S., Rhoades, J. A., \& Drasgow, F. 2000. The empowering leadership questionnaire: The construction and validation of a new scale for measuring leader behaviors. Journal of Organizational Behavior, 21: 249-269.

Barling, J., Weber, T., \& Kelloway, E. K. 1996. Effects of transformational leadership training on attitudinal and financial outcomes: A field experiment. Journal of Applied Psychology, 81: 827-832.

Bauer, D. J., Preacher, K. J., \& Gil, K. M. 2006. Conceptualizing and testing random indirect effects and moderated mediation in multilevel models: New procedures and recommendations. Psychological Methods, 11: 142-163.

Blanchard, K. H. 2007. Leading at a Higher Level. Upper Saddle River, NJ: Prentice-Hall.

Bliese, P. D. 2000. Within-group agreement, non-independence, and reliability: Implications for data aggregation and analysis. In K. J. Klein \& S. W. J. Kozlowski (Eds.), Multilevel theory, research and methods in organizations: $349-381$. San Francisco: Jossey-Bass.

Bliese, P. D., \& Ployhart, R. E. 2002. Growth modeling using random coefficient models: Model building, testing, and illustrations. Organizational Research Methods, 5: 362-387.

Bobic, M. P., \& Davis, W. E. 2003. A kind word for Theory X: Or why so many newfangled management techniques quickly fail. Journal of Public Administration Research and Theory, 13: 239-264. 
Bunderson, J. S., \& Sutcliffe, K. M. 2003. When to put the brakes on learning? Harvard Business Review, 81: 20-21.

Burke, C. S., Stagl, K. C., Klein, C., Goodwin, G. F., Salas, E., \& Halpin, S. M. 2006. What type of leadership behaviors are functional in teams? A meta-analysis. Leadership Quarterly, 17: 288-307.

Burke, C.S., Stagl, K.C., Salas, E., Pierce, L., \& Kendall, D. 2006. Understanding team adaptation: A conceptual analysis and model. Journal of Applied Psychology, 91: 11891207.

Chen, G., Kirkman, B. L., Kanfer, R., Allen, D., \& Rosen, B. 2007. A multilevel study of leadership, empowerment, and performance in teams. Journal of Applied Psychology, 92: 331-346.

Chen, G.; Sharma, P. N.; Edinger, S.; Shapiro, D. L.; Farh, J. L. 2011. Motivating and demotivating forces in teams: Cross-level influences of empowering leadership and relationship conflict. Journal of Applied Psychology, 96: 541-557.

Cohen, S. G., Chang, L., \& Ledford, G. E., Jr. 1997. A hierarchical construct of self-management leadership and its relationship to quality of work life and perceived work group effectiveness. Personnel Psychology, 50: 275-308.

Cotton, J. L., Vollrath, D. A., Lengnick-Hall, M. L., \& Froggatt, K. L. 1990. Fact: The form of participation does matter - a rebuttal to Leana, Locke, and Schweiger. Academy of Management Review, 15: 147-153.

Cox, J. F., and Sims, H. P., Jr. 1996. Leadership and team citizenship behavior: A model and measures. In M. M. Beyerlein \& D. A. Johnson (Eds.), Advances in Interdisciplinary Studies of Work Teams, Vol. 3: 1-14. Greenwich, CT: JAI Press. 
Davison, R. B., Hollenbeck, J. R., Barnes, C. M., Sleesman, D. J., \& Ilgen, D. R. in press. Coordinated action in multi-team systems. Journal of Applied Psychology.

Durham, C. C., Knight, D., \& Locke, E. A. 1997. Effects of leader role, team-set goal difficulty, efficacy, and tactics on team effectiveness. Organizational Behavior and Human Decision Processes, 72: 203-231.

Edmondson, A. C. 1999. Psychological safety and learning behavior in work teams. Administrative Science Quarterly, 44: 350-383.

Edmondson, A. C., Bohmer, R. M., \& Pisano, G. P. 2001. Disrupted routines: Team learning and new technology implementation in hospitals. Administrative Science Quarterly, 46: 685716.

Edwards, B. D., Day, E. A., Arthur, W., \& Bell, S. T. 2006. Relationships among team ability composition, team mental models, and team performance. Journal of Applied Psychology, 91: 727-736.

Ellis, A. P. J. 2006. System breakdown: The role of shared mental models and transactive memory in the relationship between acute stress and tem performance. Academy of Management Journal, 49: 576-589.

Ensley, M. D., Hmieleski, K. M., \& Pearce, C. L. 2006. The importance of vertical and shared leadership within new venture top management teams: Implications for the performance of startups. Leadership Quarterly, 17: 217-231.

Espinosa, J. A., Lerch, F. J., \& Kraut, R. E. 2004. Explicit versus implicit coordination mechanisms and task dependencies: One size does not fit all. In E. Salas \& S. M. Fiore (Eds.), Team Cognition: Understanding the Factors that Drive Process and Performance: 107-129. Washington, DC: American Psychological Association. 
Evans, M. 1970. The effects of supervisory behavior on the path-goal relationship. Organizational Behavior and Human Performance, 5: 277-298.

Fiedler, F. E. 1968. Personality and situational determinants of leadership effectiveness. In D. Cartwright \& A. Zanders (Eds.), Group dynamics: Research and theory: 362-380. New York: Harper and Row.

Gibson, C. \& Vermeulen, F. 2003. A healthy divide: Subgroups as a stimulus for team learning behavior. Administrative Science Quarterly, 48: 202-239.

Goodson, J. R., McGee, G. W., \& Cashman, J. F. 1989. Situational leadership theory: A test of leadership prescriptions. Group \& Organization Studies, 14: 446 - 461.

Graen, G. B., \& Scandura, T. A. 1987. Towards a psychology of dyadic organizing. Research in Organizational Behavior, 9: 175-208.

Gratton, L., \& Erickson, T. J. 2007. Eight ways to build collaborative teams. Harvard Business Review, 11: 101-109.

Hersey, P., \& Blanchard, K. H. 1969. Management of Organizational behavior: Utilizing Human Resources. Englewood Cliffs, NJ: Prentice-Hall.

Hersey, P., \& Blanchard, K. H. 1982. Management of Organizational behavior: Utilizing Human Resources (4 ${ }^{\text {th }}$ ed.). Englewood Cliffs, NJ: Prentice-Hall.

Hinsz, V. B., Tindale, R. S., \& Vollrath, D. A. 1997. The emerging conceptualization of groups as information processors. Psychological Bulletin, 121: 43-64.

House, R.J. 1971. A path-goal theory of leader effectiveness. Administrative Science Quarterly, 16: $321-338$.

House, R. J. 1996. Path-goal theory of leadership: Lessons, legacy, and a reformulated theory. Leadership Quarterly, 7: 323-352. 
Ilgen, D. R., Hollenbeck, J. R., Johnson, M., \& Jundt, D. 2005. Teams in organizations: From Input-Process-Output Models to IMOI Models. Annual Review of Psychology, 56: 517-543.

James, L. R. 1982. Aggregation bias in estimates of perceptual agreement. Journal of Applied Psychology, 67: 219-229.

James, L. R., Demaree, R. G., \& Wolf, G. 1984. Estimating within group interrater reliability with and without response bias. Journal of Applied Psychology, 69: 85-98.

Johnson, M., Hollenbeck, J., Humphrey, S., Ilgen, D., Jundt, D., \& Meyer, C. 2006. Cutthroat cooperation: Asymmetrical adaptation to changes in team reward structures. Academy of Management Journal, 49: 103-119.

Kahai, S. S., Sosik, J. J., \& Avolio, B. J. 2004. Effects of participative and directive leadership in electronic groups. Group \& Organization Management, 29: 67-105.

Katz, D., \& Kahn, R. L. 1978. The Social Psychology of Organizations (2 ${ }^{\text {nd }}$ ed). New York: Wiley.

Katzenbach, J. R., \& Smith, D. K. 1993. The Wisdom of Teams: Creating the High Performance Organization. Cambridge, MA: Harvard Business Press.

Kirkman, B. L., \& Rosen, B. 1999. Beyond self-management: Antecedents and consequences of team empowerment. Academy of Management Journal, 42: 58-74.

Kirkman, B. L., Rosen, B., Tesluk, T., \& Gibson, C. 2004. The impact of team empowerment on virtual team performance: The moderating role of face-to-face interaction. Academy of Management Journal, 47: 175-192.

Klein, K. J., Ziegert, J. C., Knight, A. P., \& Xiao, Y. 2006. Dynamic Delegation: Shared, hierarchical, and deindividualized leadership in extreme action teams. Administrative Science Quarterly, 51: 590-621. 
Klein, K., \& Kozlowski, S. W. J. 2000. Multilevel Theory, Research and Methods in Organizations. San Francisco: Jossey-Bass.

Korsgaard, M. A., Schweiger, D. M., \& Sapienza, H. J. 1995. Building commitment, attachment, and trust in strategic decision-making teams: The role of procedural justice. Academy of Management Journal, 38: 60-84.

Kozlowski, S. W. J., Gully, S. M., Salas, E., \& Cannon-Bowers, J. A. 1996. Team leadership and development: Theory, principles, and guidelines for training leaders and teams. In M. M. Beyerlein, D. Johnson, \& S. T. Beyerlein (Eds.), Interdisciplinary Studies of Work Teams: 253-291. Greenwich, CT: JAI Press.

Kozlowski, S. W. J., Gully, S. M., Nason, E. R. \& Smith, E. M. 1999. Developing adaptive teams : A theory of compilation and performance across levels and time. In D. R. Ilgen \& E. D. Pulakos (Eds.), The Changing Nature of Performance: Implications for Staffing, Personnel Actions, \& Development: 240-292. San Francisco: Jossey-Bass.

Leana, C. R. 1987. Power relinquishment versus power sharing: Theoretical clarification and empirical comparison of delegation and participation. Journal of Applied Psychology, 72: 228-233.

Leana, C. R., Locke, E. A., \& Schweiger, D. M. 1990. Fact and fiction in analyzing research on participative decision making: a critique of Cotton, Vollrath, Lengnick-Hall and Jennings. Academy of Management Review, 15: 137-146.

LePine, J. A. 2003. Team adaptation and post-change performance: Effects of team composition in terms of members' cognitive ability and personality. Journal of Applied Psychology, 88: 27-39. 
MacKinnon, D. P., Fairchild, A. J., \& Fritz, M. S. 2007. Mediation analysis. Annual Review of Psychology, 58: 593-614.

Manz, C. C., \& Sims, H. P. Jr. 1986. Beyond imitation: Complex behavioral and affective linkages resulting from exposure to leadership training models. Journal of Applied Psychology, 71: 571-578.

Manz, C. C., \& Sims, H. P. Jr. 1987. Leading workers to lead themselves: The external leadership of self-managing work teams. Administrative Science Quarterly, 32: 106-129.

Marks, M. A., Mathieu, J. E., \& Zaccaro, S. J. 2001. A temporally based framework and taxonomy of team processes. Academy of Management Review, 26: 356-376.

Marks, M. A., Zaccaro, S. J., \& Mathieu, J. E. 2000. Performance implications of leader briefings and team interaction training for adaptation to novel environments. Journal of Applied Psychology, 6: 971-986.

Mathieu, J. E., Ahearne, M., \& Taylor, S. R. 2007. A longitudinal cross-level model of leader and salesperson influences on sales force technology use and performance. Journal of Applied Psychology, 92: 528-537.

Mathieu, J. E., Gilson, L. L., \& Rudy, T. M. 2006. Empowerment and team effectiveness: an empirical test of an integrated model. Journal of Applied Psychology, 91: 97-108.

Mathieu, J. E., Heffner, T. S., Goodwin, G. F., Cannon-Bowers, J. A., \& Salas, E. 2005. Scaling the quality of teammates' mental models: equifinality and normative comparisons. Journal of Organizational Behavior, 26: 37-56.

Mathieu, J. E., Maynard, M. T., Rapp, T., \& Gilson, L. 2008.Team effectiveness 1997-2007: A review of recent advancements and a glimpse into the future. Journal of Management, 34: 410-476. 
McIntyre, R. \& Salas, E. 1995. Measuring and managing for team performance: Emerging principles from complex environments. In R. Guzzo and E. Salas (Eds.), Team Effectiveness and Decision Making in Organizations: 9-45. San Francisco, CA: JosseyBass.

Mohammed, S., Klimoski, R., \& Rentsch, J. R. 2000. The measurement of team mental models: We have no shared schema. Organizational Research Methods, 3: 123-165.

Moon, H., Hollenbeck, J. R., Humphrey, S. E., Ilgen, D. R., West, B. J., Ellis, A. P. J., \& Porter, C. O. L. H. 2004. Asymmetric adaptability: Dynamic team structures as one-way streets. Academy of Management Journal, 47: 681-696.

Muczyk, J. P. \& Reimann, B. C. 1987. The case for directive leadership. Academy of Management Executive, 1: 301-311.

Muller, D., Judd, C. M., \& Yzerbyt, V. Y. 2005. When moderation is mediated and mediation is moderated. Journal of Personality \& Social Psychology, 89: 852-863.

Northouse, P. G. 2007. Leadership: Theory and practice. Thousand Oaks, CA: Sage Publications.

Pearce, C., Sims, H. P., Cox, J., Ball, G., Schnell, E., \& Smith, K. 2003. Transactors, transformers and beyond. Journal of Management Development, 22: 273-307.

Pearsall, M. J., Ellis, A. P. J., \& Bell, B. S. 2010. Building the infrastructure: The effects of role identification behaviors on team cognition development and performance. Journal of Applied Psychology, 95: 192-200.

Preacher, K. J., Rucker, D. D., \& Hayes, A. F. 2007. Addressing moderated mediation hypotheses: Theory, methods, and prescriptions. Multivariate Behavioral Research, 42: $185-227$. 
Sagie, A. 1996. Effects of leader's communication style and participative goal setting on performance and attitudes. Human Performance, 9: 51-64.

Sagie, A. 1997. Leader direction and employee participation in decision making: Contradictory or compatible practices? Applied Psychology: An International Review, 46: 387-452.

Sagie, A., Zaidman, N. Amichai-Hamburger, Y., Te’eni, D., \& S., D. G. 2002. An empirical assessment of the loose-tight leadership model: quantitative and qualitative analyses. Journal of Organizational Behavior, 3: 303-320.

Seibert, S. E., Wang, G., \& Courtright, S. H. 2011. Antecedents and consequences of psychological and team empowerment in organizations: A meta-analytic review. Journal of Applied Psychology, 96: 981-1003.

Shrout, P. E., \& Bolger, N. 2002. Mediation in experimental and nonexperimental studies: New procedures and recommendations. Psychological Methods, 7: 422-445.

Sims, H. P., Faraj, S., \& Yun, S. 2009. When should a leader be directive or empowering? How to develop your own situational theory of leadership. Business Horizons, 52: 149-158.

Somech, A. 2006. The effects of leadership style and team process on performance and innovation in functionally heterogeneous teams. Journal of Management, 32: 132-157.

Sosik, J. J., Avolio, B. J., \& Kahai. S. S. 1997. Effects of leadership style and anonymity on group potency and effectiveness in a group decision support system environment. Journal of Applied Psychology, 82: 89-103.

Spreitzer, G. M. 1995. Psychological empowerment in the workplace: Dimensions, measurement, and validation. Academy of Management Journal, 38: 1442-1465. 
Spreitzer, G. M. 2008. Taking stock: A review of more than twenty years of research on empowerment at work. In J. Barling \& C.L. Cooper (Eds.), The Sage Handbook of Organizational Behavior: 73-88.

Srivastava, A., Bartol, K. M., \& Locke, E. A. 2006. Empowering leadership in management teams: Effects on knowledge sharing, efficacy and performance. Academy of Management Journal, 49: 1239 - 1251.

Sundstrom, E. 1999. The challenges of supporting work team effectiveness. In E. Sundstrom and Associates (Eds.), Supporting Work Team Effectiveness: 3-23. San Francisco, CA: JosseyBass.

Thomas, K. W., \& Velthouse, B. A. 1990. Cognitive elements of empowerment: An "interpretive" model of intrinsic task motivation. Academy of Management Review, 15: $666-681$.

Thompson, G., \& Vecchio, R. P. 2009. Situational leadership theory: A test of three versions. The Leadership Quarterly, 20: 837-848.

Towler, A. J. 2003. Effects of charismatic influence training on attitudes, behavior, and performance. Personnel Psychology, 56: 363-381.

Vecchio, R. P. 1987. Situational leadership theory: An examination of a perspective theory. Journal of Applied Psychology, 72: 444-451.

Vroom, V. H., \& Jago, A. G. 1988. The New Leadership: Managing Participation in Organizations. Englewood Cliffs, NJ: Prentice Hall.

Wagner, J. A. 1994. Participation's effects on performance and satisfaction: a reconsideration of the evidence. Academy of Management Review, 19: 312-330. 
Walumbwa, F. O., \& Schaubroeck, J. 2009. Leader personality traits and employee voice behavior: Mediating roles of ethical leadership and work group psychological safety. Journal of Applied Psychology, 94: 1275-1286.

Yukl, G. A. 1998. Leadership in Organizations (4 ${ }^{\text {th }}$ ed.). Englewood Cliffs, NJ: Prentice Hall. Yukl, G. 2010. Leadership in Organizations (7th ed.). Upper Saddle River, NJ: Prentice Hall. Yukl, G., \& Falbe, C. M. 1991. Importance of different power sources in downward and lateral relations. Journal of Applied Psychology, 76, 416-423.

Yukl, G. A., \& R. Lepsinger. 2004. Flexible Leadership: Creating Value by Balancing Multiple Challenges and Choices. San Francisco: Jossey-Bass.

Yun, S., Faraj, S., \& Sims, H. P. 2005. Contingent leadership and effectiveness of trauma resuscitation teams. Journal of Applied Psychology, 90: 1288-1296.

Zaccaro, S. J., Rittman, A. L., \& Marks, M. A. 2001. Team leadership. Leadership Quarterly, 12: 451-483.

Zhang, X., \& Bartol, K. M. 2010. Linking empowering leadership and employee creativity: the influence of psychological empowerment, intrinsic motivation, and creative process engagement. Academy of Management Journal, 53: 107-128. 
TABLE 1

Descriptive Statistics of the Study Variables

\begin{tabular}{|c|c|c|c|c|c|c|c|c|c|c|c|}
\hline Variables & $M$ & $S D$ & 1 & 2 & 3 & 4 & 5 & 6 & 7 & 8 & 9 \\
\hline 1. Leadership Condition & .5 & .50 & & & & & & & & & \\
\hline 2. Team Cognitive Ability & 3.49 & .18 & .15 & & & & & & & & \\
\hline 3. Computer Game Experience & 3.61 & .56 & -.04 & -.07 & & & & & & & \\
\hline 4. Team Learning (rounds 6-10) & 76.78 & 25.04 & $.26^{*}$ & .02 & .10 & & & & & & \\
\hline 5. Behavioral Coordination (rounds $6-10$ ) & 25.08 & 7.2 & .12 & -.04 & -.11 & $.24^{*}$ & & & & & \\
\hline 6. Team Empowerment & 3.98 & .38 & $.45^{* *}$ & -.12 & .13 & .12 & .07 & & & & \\
\hline 7. Team Mental Models & 4.85 & 1.14 & $.25^{*}$ & -.08 & .09 & .21 & .02 & .19 & & & \\
\hline 8. Mid-Point Team Performance & 1.91 & 17.57 & $-.24^{*}$ & .01 & -.18 & .02 & -.08 & -.09 & -.11 & & \\
\hline 9. Final Team Performance & 10.97 & 51.58 & .03 & .11 & .16 & $.24^{*}$ & .17 & .12 & .23 & $.29^{*}$ & - \\
\hline
\end{tabular}

$\mathrm{N}=60$. Leadership condition is a dichotomous variable comparing empowering leadership (coded as 1) with directive leadership (coded as 0 ). Team Learning is the total number of team learning behaviors during the team compilation phase (rounds 6-10). Behavioral Coordination is the total number of coordinated missions during the team compilation phase (rounds 6-10).

$* \mathrm{p}<.05, * * \mathrm{p}<.01$ 
TABLE 2

Results of Random Coefficient Models for Team Performance over Time

\begin{tabular}{lccr}
\hline Model and Parameter & $\begin{array}{c}\text { Parameter } \\
\text { Estimate }\end{array}$ & $S E$ & $t$ \\
\hline Final Level 2 Model & -28.18 & 26.31 & -1.07 \\
Intercept & $2.13^{*}$ & 1.01 & 2.11 \\
Time & 2.60 & 6.63 & .39 \\
Team Cognitive Ability & 4.40 & 4.20 & 1.05 \\
Computer Game Experience & -3.42 & 3.00 & -1.14 \\
Leadership & $.34^{*}$ & .16 & 2.12 \\
Time * Leadership &
\end{tabular}

For all Level 1 parameter estimates, $d f=538$; for cross-level interaction parameters in Level 2 analyses, $d f=538$, for parameters preceding intercept variation in Level 2 analyses, $d f=56$. Leadership is a dichotomous variable with $1=$ Empowering leadership, and $0=$ Directive leadership. ${ }^{*} \mathrm{p}<.05,{ }^{* *} \mathrm{p}<.01$ 
TABLE 3

Results of Random Coefficient Models for Mediators Testing

\begin{tabular}{lcrc}
\hline Model and Parameter & $\begin{array}{c}\text { Parameter } \\
\text { Estimate }\end{array}$ & $S E$ & $t$ \\
\hline Final Level 2 Model & -37.32 & 82.26 & -.45 \\
Intercept & 3.58 & 1.92 & 1.86 \\
Time & 21.68 & 20.45 & 1.06 \\
Team Cognitive Ability & -1.23 & 12.86 & -.10 \\
Computer Game Experience & 12.37 & 17.69 & .70 \\
Leadership & 1.24 & 2.59 & .50 \\
Time * Leadership & $.39^{*}$ & .17 & 2.17 \\
Team Learning & $1.26^{* *}$ & .47 & 2.69 \\
Behavioral Coordination &
\end{tabular}

For all Level 1 parameter estimates, $d f=234$; for cross-level interaction parameters in Level 2 analyses, $d f=234$, for parameters preceding intercept variation in Level 2 analyses, $d f=55$. Leadership is a dichotomous variable with $1=$ Empowering leadership, and $0=$ Directive leadership.

" $\mathrm{p}<.05$

$\mathrm{p}<.01$ 
TABLE 4

Results of GLS for Testing Team Empowerment and Team Mental Models as Mediators

\begin{tabular}{lccc}
\hline Variable & $\begin{array}{c}\text { Model 1: } \\
\text { Empowerment as } \\
\text { Outcome }\end{array}$ & $\begin{array}{c}\text { Model 2: } \\
\text { TMM as Outcome }\end{array}$ & $\begin{array}{c}\text { Model 3: } \\
\text { Performance as } \\
\text { Outcome }\end{array}$ \\
\hline Intercept & $1.96^{* *}$ & 1.61 & $-15.47^{* *}$ \\
Team Cognitive Ability & $.51^{*}$ & .07 & 3.31 \\
Computer Game Experience & .07 & $.75^{*}$ & .08 \\
Leadership & $.12^{*}$ & $.53^{* *}$ & 15.58 \\
Team Empowerment & & & $26.14^{* *}$ \\
Team Mental Models (TMM) & & & $2.26^{*}$ \\
Time & & & 3.87 \\
Time*Leadership & & 295 & 2.60 \\
Degrees of Freedom (df) & 295 & & 285 \\
\hline $\mathrm{p}<.05$ & & &
\end{tabular}




\section{FIGURE 1}

\section{The Effects of Leadership in Team Development Phases}

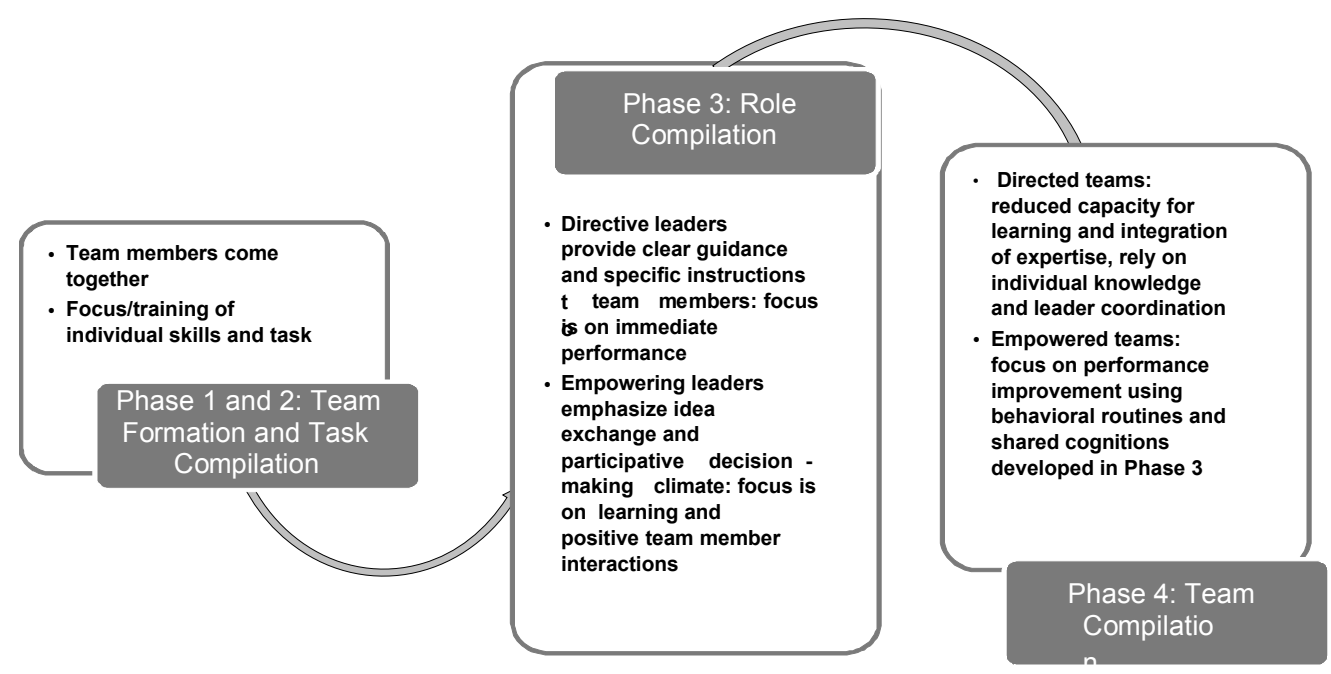

Adapted from Kozlowski et al. (1999) 


\section{FIGURE 2}

\section{Leadership Development Simulator Screen}

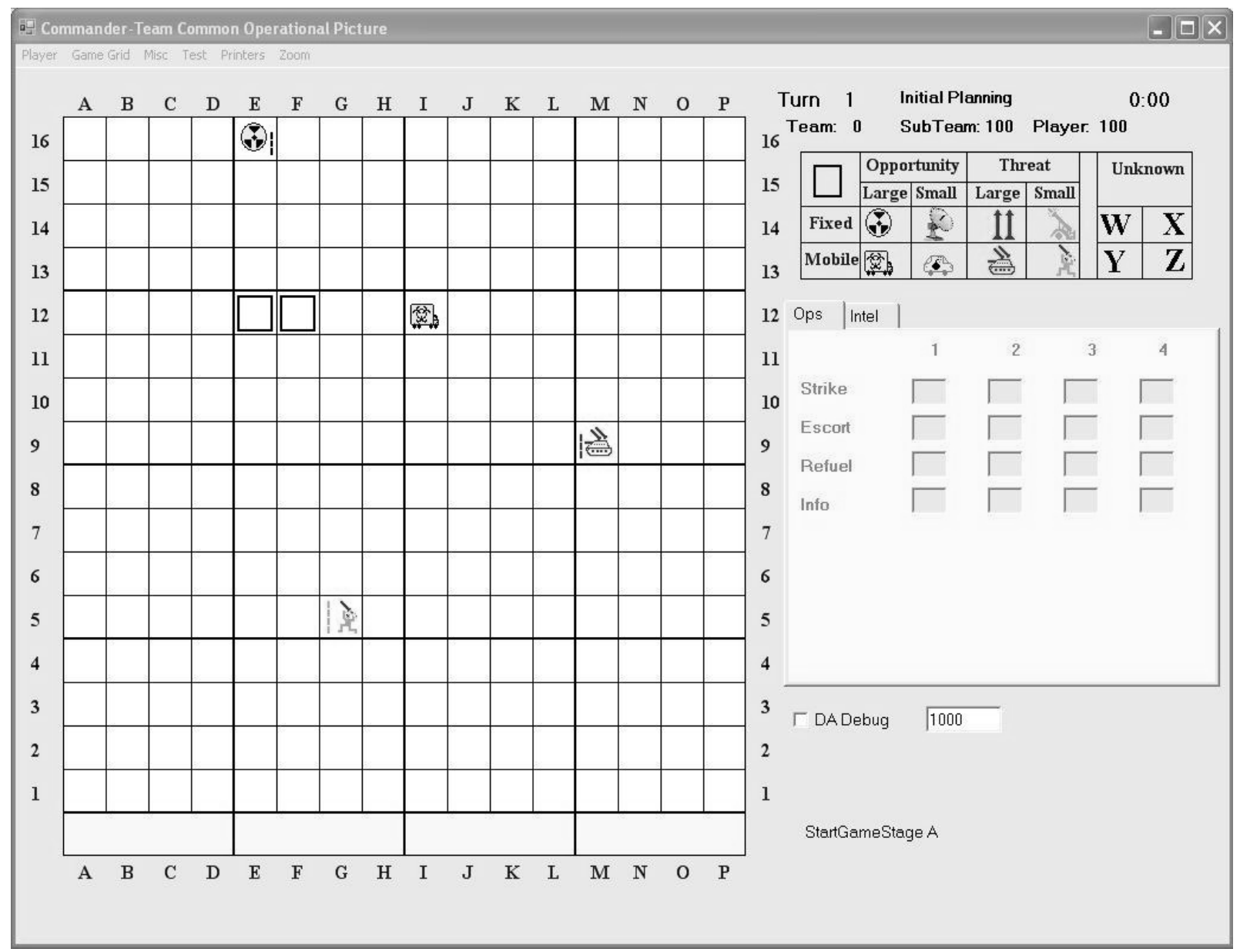




\section{FIGURE 3}

The Interactive Influence of Time and Leadership on Team Performance

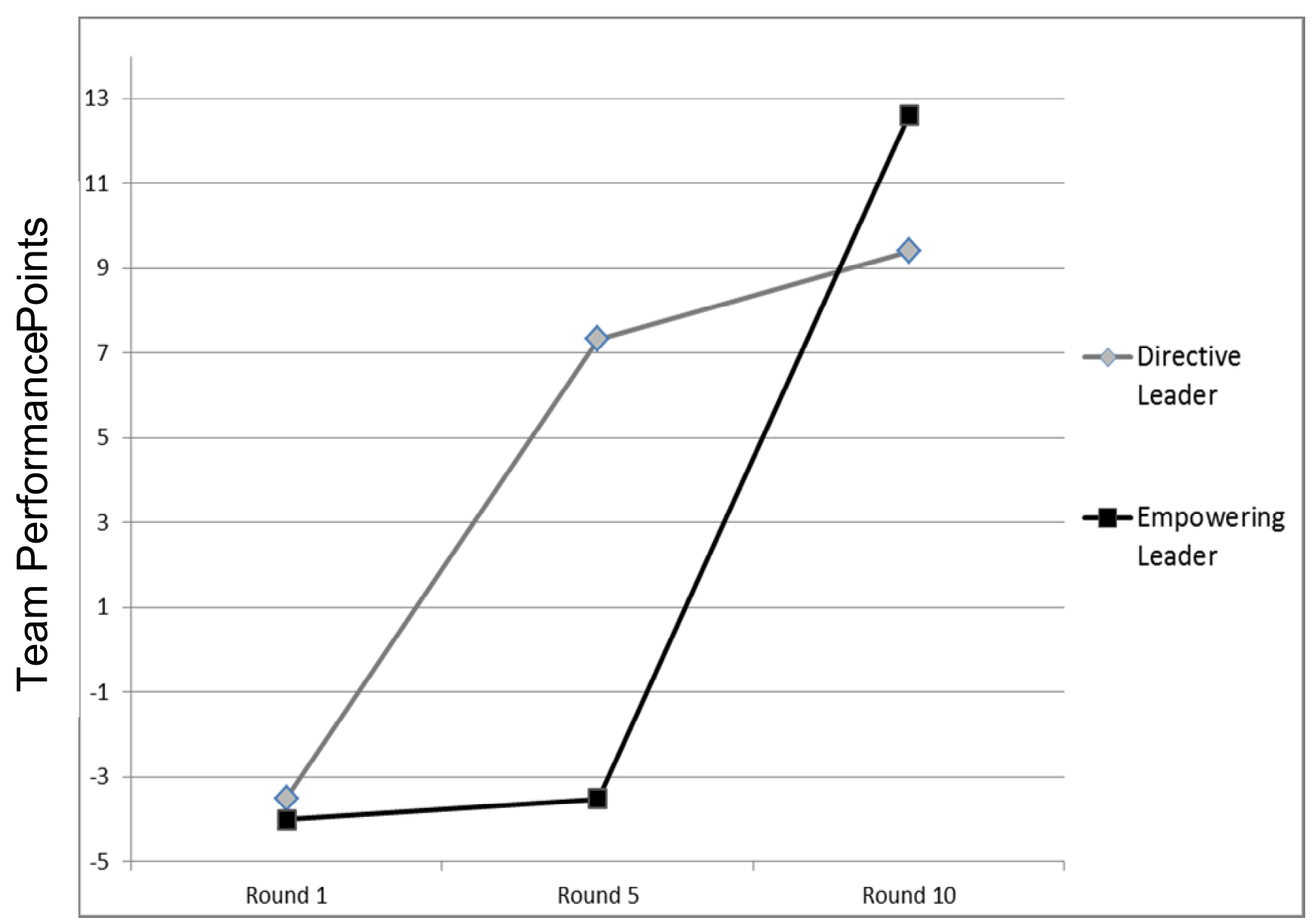




\section{Appendix}

\section{Pre-scripted Leader Behavior Prompter Phrases}

\begin{tabular}{|c|c|}
\hline Directive Leader Suggested Phrases & Empowering Leader Suggested Phrases \\
\hline $\begin{array}{l}\text { - OK, good performance so far. } \\
\text { - } \quad \text { Now, I need you to listen carefully } \\
\text { to my instructions so we can do } \\
\text { better in the next rounds. } \\
\text { - } \text { I expect you to stick to your roles } \\
\text { and execute them with great } \\
\text { diligence. } \\
\text { - Make sure you know what your } \\
\text { own assets are and operate them } \\
\text { accordingly. } \\
\text { I want the intelligence players to } \\
\text { send all their assets early in the } \\
\text { round in the upper/lower half of the } \\
\text { grid. } \\
\text { Operation players, make sure you } \\
\text { refuel when operating in the upper } \\
\text { grid. } \\
\text { Operation players, pay close } \\
\text { attention to the mobile targets. } \\
\text { Our tactics for the next round is ... } \\
\text { you all need to follow this tactic. }\end{array}$ & $\begin{array}{l}\text { - OK, well done so far, team. } \\
\text { - I encourage all of you to } \\
\text { communicate more in order to } \\
\text { improve our team performance. } \\
\text { - OK, let's discuss our performance } \\
\text { and decide what we want to do in } \\
\text { order to improve it. Any ideas? } \\
\text { - Let's try to work together - we } \\
\text { need ideas. } \\
\text { - We need all the information you } \\
\text { have on the table - tell your team } \\
\text { members what you see and think. } \\
\text { How about we try something more } \\
\text { creative for the next round? What } \\
\text { do you think? } \\
\text { We need to work together as a team } \\
\text { - it is up to us to find a way to get } \\
\text { more points. }\end{array}$ \\
\hline
\end{tabular}


Natalia M. Lorinkova (natalia.lorinkova@wayne.edu) is an assistant professor in the Management and IS Department in the School of Business Administration at Wayne State University. She received her PhD in Management from the R. H. Smith School of Business, University of Maryland. Her primary research interest is in the area of leadership, with an emphasis on change, developmental and empowering leadership.

Matthew J. Pearsall (matthew_pearsall@unc.edu) is an assistant professor in the Organizational Behavior department in the Kenan-Flagler Business School at the University of North Carolina at Chapel Hill. He received his Ph.D. from the University of Arizona in Management. His research interests include the development of emergent states in teams and the antecedents and outcomes of shared cognition.

Henry P. Sims, Jr. is Professor Emeritus at the R H Smith School of Business, University of Maryland. He received his $\mathrm{PhD}$ from Michigan State University. His research focuses on leadership and teamwork, especially the issue of how empowering leadership and teamwork can lead to self-leadership at both the individual and team level. 